\author{
Andrea Bassi \\ Giulia Ganugi \\ Riccardo Prandini \\ University of Bologna \\ University of Bologna \\ University of Bologna
}

\title{
CO-DESIGN AND CO-PRODUCTION OF PUBLIC SERVICE. THE PREVENTION OF CHILDHOOD OBESITY IN REGGIO EMILIA - ITALY ${ }^{1}$
}

DOI: $10.2478 /$ ppsr-2021-0013

\begin{abstract}
Authors
Andrea Bassi-(PhD in Sociology and Social Policy) is Associate Professor of Sociology. His research interests include: studies on nonprofit organizations in the field of social and health services, particularly concerning the relationships between public administration and nonprofit deliverers; and systems of measurement of organizational performance and social impact of nonprofit organizations.
\end{abstract}

ORCID no. 0000-0003-3255-959X

e-mail: andrea.bassi7@unibo.it

Giulia Ganugi-Research fellow. Joint PhD in Sociology and Social Research at the University of Bologna, and in Science: Geography at KU Leuven. Her research interests focus on processes of social innovation, co-creation and co-production, changes of governance models and the empowerment of local communities, participation and citizenship, social and welfare policies.

ORCID no. 0000-0003-4650-5023

e-mail: giulia.ganugi2@unibo.it

Riccardo Prandini-Professor in Sociology of Culture and Communication. His research interests focus on cultural transformations of Italian families, changes of welfare national systems, personalized social services, the civil spheres, the semantics of intimate relationships, the emergence and institutionalization of corporate and territorial welfare.

ORCID no. 0000-0002-2581-3476

e-mail: riccardo.prandini@unibo.it

\begin{abstract}
The paper illustrates an empirical research project concerning the co-creation process in Reggio Emilia's public services and their efforts to reduce childhood obesity. The research is based on a participative evaluation research methodology. The project has been implemented within the framework of the CoSIE project, funded by the Horizon 2020 Research Program-Innovation Action. It has been led by the Local Health Unit (LHU) of Reggio Emilia, a mid-size town in north-eastern Italy, and Cup2000/Lepida, a public/private corporation delivering ICT for health service in the Emilia-Romagna Region.

The empirical research has been conducted by the University of Bologna, using a mixed method multi-dimensional strategy and combining the Action-Research tradition with the approach of the Theory of Change.
\end{abstract}

$1 \quad$ Andrea Bassi has written the sections 1 and 2; Riccardo Prandini has written the sections 3 and 6; Giulia Ganugi has written the sections 4 and 5. 
The theoretical framework reflects on the co-creation process, distinguishing between its different phases. In particular, it defines the co-production and the co-design phase, operationalising them with the concepts of System Integration and Social Integration. This linkage allows the analysis of the involvement of institutional stakeholders and final users in the co-creation process.

Many factors including the actors' identity, the participation modalities and the impact of each stakeholder on the service, contribute to the model of co-creation in "the shadow of institutions", characterised by a low level of Social Integration and a high level of System Integration.

Keywords: co-creation, co-production, co-design, evaluation research, social integration, system integration

\section{Introduction}

The pilot on child obesity in Reggio Emilia aims to reduce childhood obesity in the province through the co-creation of a network of service delivery agencies. A multilevel and multi-target program for prevention and management of childhood obesity, the Bimbi Molto In forma (BMInforma) program, is already running in the province. This program aims to link health promotion and primary prevention (building an environment where healthy choices are easier) to secondary prevention (counselling and motivational interviews of overweight children and multidisciplinary team interventions for obese children) and care of obesity complications.

Figure 1. Phases and sub-phases of the Italian Pilot implementation.

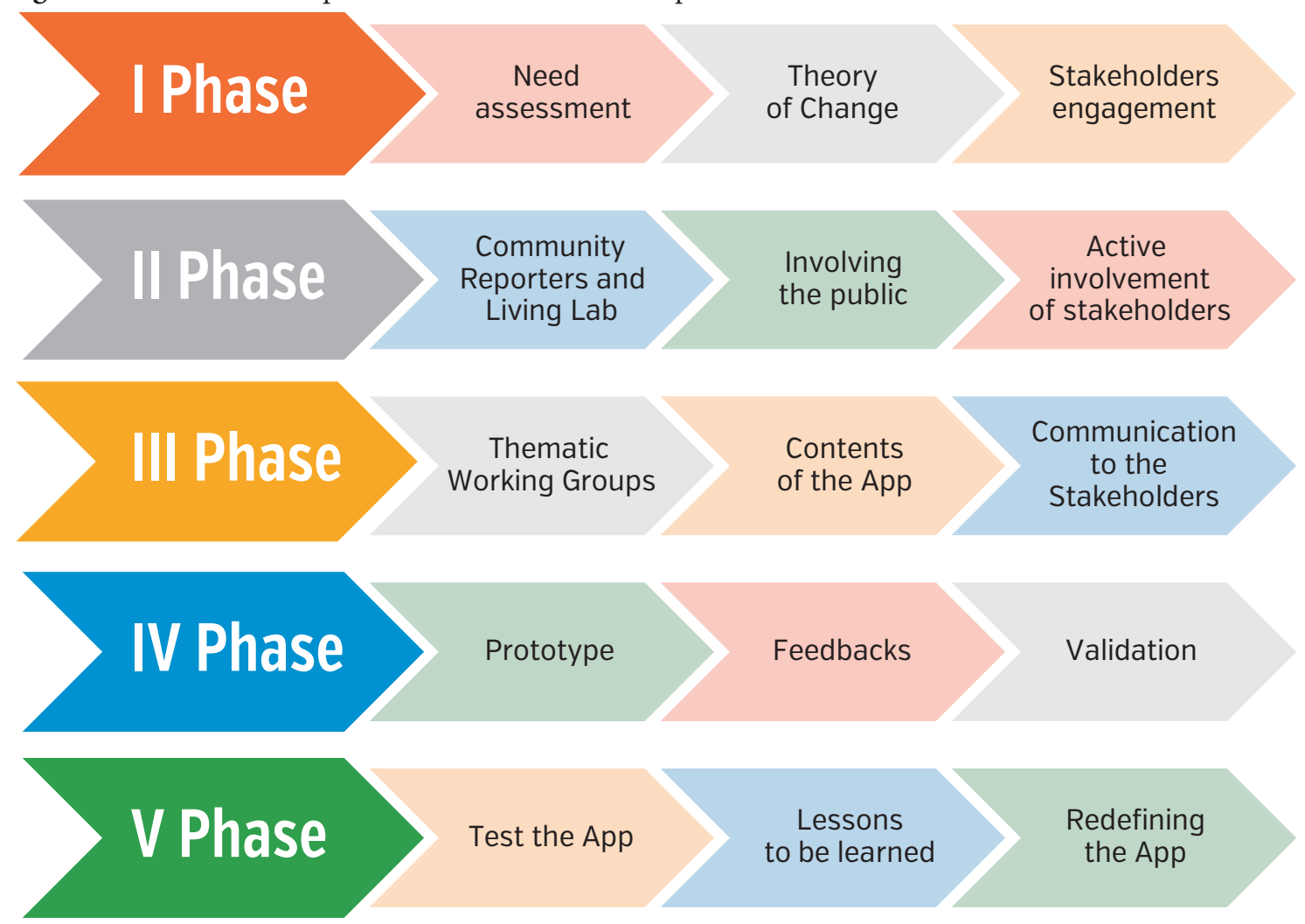

The pilot project consists of the implementation of co-creation strategies to improve and develop the BMInforma program. One of these strategies is the co-production of an app to 
facilitate the communications between parents, paediatricians and the Health Authority, while also promoting healthy behaviours through physical activity opportunities. The app will ensure transparency and accountability according to the ethical requirements of the Italian Health System. Moreover, the project intends to advocate health promotion and a healthy urban environment to local policy makers.

The proposed actions to be launched in the Pilot have been identified and divided as five main phases (see Figure 1 below): Phase I: Identification of the needs (March 2018-August 2018); Phase II: Building the network, translate needs into service contents (September 2018-February 2019); Phase III: Development of the first digital tool (App) prototype and re-definition of the service organisation network (March 2019-February 2020); Phase IV: Testing the App (March '20-August '20); Phase V: Diffusion of the app (Sept '20-end Nov '20). In addition, a final project phase has been planned to include actions that will occur after the project's end.

Due to the Covid-19 pandemic, the activities of phase IV have been postponed. So, the entire Pilot was delayed by four months.

This research analyses the three phases which have already been implemented. Based on a theoretical model which merges the dimensions of systemic and social integration, our hypothesis states that a complete "cycle" of co-creation (as defined in the text) should encompass both types of high-level integration.

On the contrary, our case study presents a high systemic integration and a low social integration, demonstrating how the "cycle" is incomplete. In the discussion we will analyse the conditions which lead to this configuration. To conclude we briefly reflect on three other different configurations of co-creation.

\section{Methodology}

The Cosie project employed a mixed method multi-dimensional strategy, combining the Action-Research tradition with the framework of the Theory of Change (See Figure 2 and Table 1). This innovative research strategy entails the adoption of a flexible role of the research Team Unit (based at the University of Bologna), which has to switch back and forth between an "inside/internal" observation standpoint to an "outside/external" one. This research strategy implies also a very high level of reflexivity among the partners involved.

Figure 2. Participatory Evaluation Research Design

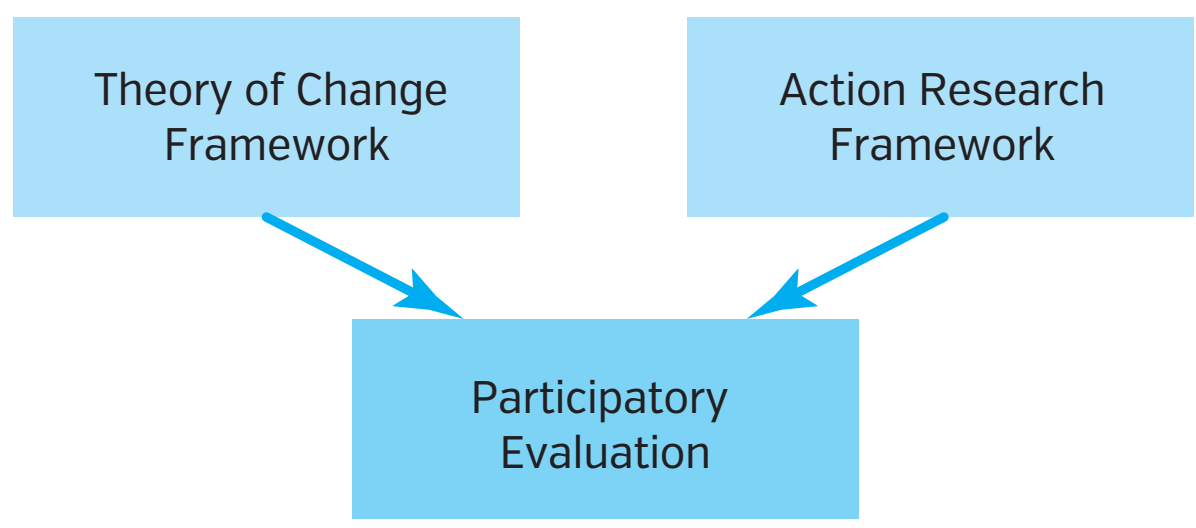


Table 1. Correspondence of research phases in the three approaches

\begin{tabular}{|c|c|c|}
\hline Theory of Change & Action Research & Participatory Evaluation \\
\hline 1. Needs Assessment & 1. Diagnosis & 1. Ex-Ante Evaluation \\
\hline 2. Theory of Change & 2. Action Planning & $\begin{array}{l}\text { 2. Negotiation of objectives, } \\
\text { rules, roles, responsibilities, } \\
\text { ownership }\end{array}$ \\
\hline 3. Process evaluation & 3. Action Implementation & $\begin{array}{l}\text { 3. In Itinere evaluation (or } \\
\text { Formative Evaluation) }\end{array}$ \\
\hline 4. Impact evaluation & 4. Identify Learning & $\begin{array}{l}\text { 4. Ex post evaluation (or } \\
\text { Summative Evaluation) }\end{array}$ \\
\hline
\end{tabular}

Participatory Action Research (PAR) 'stands conventional research methodology on its head' (Smith et al. 2010: 407). The principle of PAR is:

...that people have a right to determine their own development, hence they must 'participate meaningfully in the process of analysing their own solutions, over which they have (or share, as some would argue) power and control, in order to lead to sustainable development (Attwood 1997: 2)

The ambition behind PAR, in other words, is large and aligns well with the ambition of COSIE.

In fact:

'the impetus of this method is to attempt to restructure power relations in the research process, to honour the knowledge and strengths with/in/of diverse communities, and to challenge the dynamics of inequalities by furthering the struggle for social justice' (Gill et al.2012:1).

Ultimately, PAR 'offers a radical alternative to knowledge development in its mandate to remain a collective, self-reflective inquiry for the purpose of improving a situation' (MacDonald 2012:37).

Table two below shows the time span of the evaluation research process/cycle: before the program start (T0); during the implementation of the program (T1-T2); and after the program ended (T3).

Table 2. Different languages of Evaluation Research frameworks

\begin{tabular}{|l|l|l|l|}
\hline & \multicolumn{1}{|c|}{ Time T0 } & \multicolumn{1}{c|}{ Time T1-T2 } & \multicolumn{1}{c|}{ Time T3 } \\
\hline Evaluation Research & Ex-Ante & In Itinere & Ex-Post \\
\hline Program Evaluation & Context Analysis & Formative Evaluation & Summative Evaluation \\
\hline Theory of Change & Needs Assessment & Process Evaluation & Impact Evaluation \\
\hline
\end{tabular}


The "In itinere" evaluation can be defined also as "Formative" evaluation, since its function is to enlighten the strengths and the weaknesses of the Pilot during the implementation process, in order to introduce changes that can ameliorate the realization of the plan.

Based on a wide span of literature on co-production (Osborne et al., 2016; Tuurnas, 2015), co-creation (Voorberg et. al., 2017) and co-design (Bovaird 2007; Boyle and Harris 2009; Brandsen and Pestoff 2006), we explored several analytical frameworks (lenses) through which we collected, organised and read the data during the evaluation research/ process.

The first heuristic tool (see Fig. 3) is a general framework that allows us to detect the main actors involved in the Pilot and their networks of interrelations. It includes three level of analysis:

1. The macro level (socio-political environment) consists of a wide array of institutional actors such as: the regulatory context (national and regional level), the public administration (municipalities), the structure of the local economic system, the strength or weakness of the civil society (third sector organization, volunteering, religious institutions, etc.). This represents the structural dimension of the framework.

2. The meso level (organisational governance) refer to the powerchain and responsibilities demonstrated in the Pilot. It includes the different levels of decision making in which is articulated the main agency involved in the Pilot, meaning the Local Health Unit of Reggio-Emilia. This represents the organisational dimension of the framework.

3. The micro level (professionals and users) concerns the relationships that - at a praxis level-emerged among and between the two main subjects in the co-creation process, meaning the professionals (paediatricians, psychologists, nutritionists, etc.) and the users (families, parents, children, community actors, etc.). It represents the interaction level of the scheme.

Figure 3. Organisational Environment of the Co-creation Process

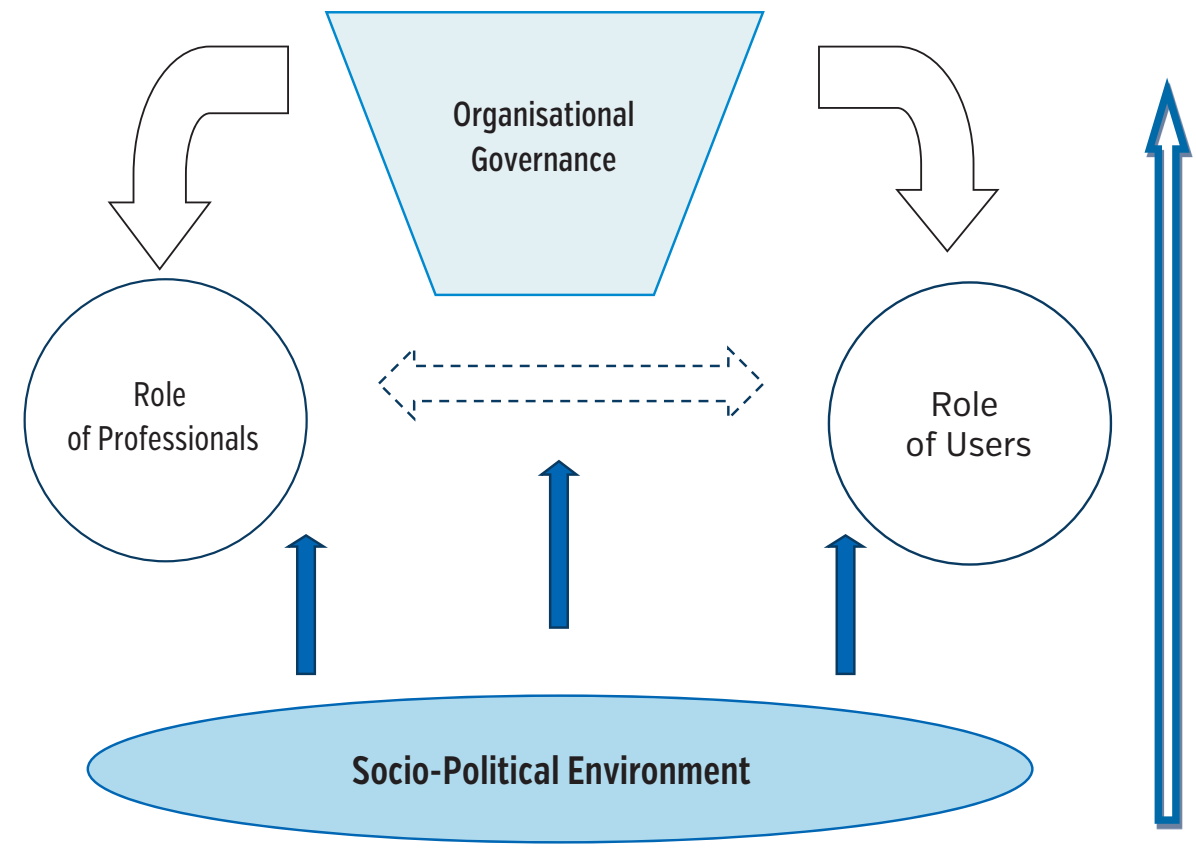


The logical framework underlined in the heuristic tools goes from the macro to the micro level through the meso level as an intermediary role and vice versa. It is theorised that the macro level (for instance a regional law or regulation) influences directly the meso level (for instance the relationship between the Epidemiology Department and the Primary care Department) and indirectly the micro level (for instance the "opening hours to the public" time schedule of the paediatricians). We know, of course, that the micro can (and often does) react towards the meso and the macro levels, but it does so in a very loose, indirect way.

In applying this scheme to our case study (Pilot), first of all we have to populate the four categories with data, coming from the empirical research (Laws, regulations, organisational structure, stakeholders, etc. etc.). From this point of view (the socio-political environment perspective), our Pilot presents an excellent opportunity. The Reggio-Emilia province has a long tradition of involvement from both public administration agencies and civil society organisations in implementing a high standard quality of ECEC (Early Childhood Education and Care) services system. This is attested by the presence in that area of several supporting Institutions in the field of health, education and social services, such as:

a) "Luoghi di prevenzione"-Emilia-Romagna Center for the Training of social and health workers ${ }^{2}$

b) "Officina educativa" (Municipal services dealing with education) $)^{3}$

c) Reggio Children (private nonprofit Foundation). ${ }^{4}$

These institutions, among others, have been involved directly or indirectly in the implementation of several programs aimed at reducing the childhood obesity in the area.

The second step of the analysis consists of the different placements of the different actors/elements/ relationships in a continuum between "opportunities/resources" (positive pole) and "constraints/obstacles" (negative pole), in relation to the co-creation process. The third step is identifying possible actions to overcome the obstacles and to foster the opportunities and resources. Finally, the fourth step of the analysis is evaluating the co-creation process, if it happened only somewhat, and eventually the reasons why it failed or partially succeeded.

Given the characteristics of the Evaluation Research approach, we utilised a variety of both qualitative and quantitative sources of data and information during our research program:

a) official documents (Laws enacted by the Regional government; Regulations enacted by municipalities);

2 It is the reference Center of the Emilia-Romagna Region for the Training of social and health workers on the themes of Health Promotion and Experimentation, monitoring and evaluation of innovative intervention methods [Centro Regionale di Didattica Multimediale per la Promozione della Salute]. http://www.luoghidiprevenzione.it/Home/

3 It is a municipality agency in support of the decision-making process of the public administration in the field of education services and youth wellbeing. https://www.comune.re.it/retecivica/urp/retecivi. nsf/PESDocumentID/1F8B2BB0EEEB956AC125772A00404542?opendocument\&FROM=SrvzsttznCltrl1 and https://www.comune.re.it/retecivica/urp/pes.nsf/web/prtmnt1?opendocument ,

4 The Reggio Children - Loris Malaguzzi Centre Foundation is an international Foundation born in 2011 at Reggio Emilia with the aim to promote solidarity through the research. Its mission is to: "improve the lives of children and communities through the promotion of quality education in Reggio Emilia, in Italy and around the world". http://www.reggiochildren.it/?lang=en . 
b) unofficial documents (projects developed within the LHA);

c) grey material (research reports, evaluation reports and so on by health units and research institutions);

d) face to face interviews with families, paediatricians, professionals, and others;

e) focus groups with representatives of the same categories;

f) on-site observation of LHA services.

In order to collect the information of d), e) and f), we used several research tools, such as:

a.i) Interview outline for face to face interviews with key experts of childhood obesity;

a.ii) Interview (or Focus Group) outline for face to face interviews with paediatricians;

a.iii) Interview (or Focus Group) outline for face to face interviews with families of obese children.

In the next sections we will illustrate the main enabling and constraining factors of the co-creation process, which we obtained from our evaluation research.

\section{The Co-creation between System Integration and Social Integration}

Governments are increasingly utilising alternative arrangements and solutions to enhance the efficiency and effectiveness of policy and service production. The aim is acknowledging the multi-actor environment and opening up the process to the market, other civil society actors and citizens (Hood 1991; Hartley 2005, Brandsen and Pestoff 2006; Williams et al. 2016; Voorberg et al. 2017). The participation of these actors in service production and delivery could be a solution to the issues described above. Indeed, citizen participation is seen to increase the efficacy of regulation, improve the provision of public goods and bolster outcomes in areas - as health and education - that straddle the boundaries between public and private, social and individual. Rearrangements of service governance is also expected to advance social justice (Fung 2015).

Within this context, from the 1980s and onwards, rising attention has been paid to the so-called new emerging paradigm for delivering public services (Bovaird 2007): co-production, and more recently, co-creation. Public services literature has offered a variety of scholarly discussions addressing different aspects of co-production ranging attempting to define it, delineating its practical aspects, examining its growth in several policy realms and surpassing its limitations with concepts such as co-creation (Williams et al. 2016; Torfing et al. 2019). Since the term was first used in Ostrom and colleagues' work (1996), co-production and co-creation have become catchwords. In the strict sense of the term, co-production in the public sector refers to the interactive process through which the providers and users of public services apply their different resources and capabilities in its production and delivery. Co-production concerns the growing organised involvement of citizens in the production of their own welfare services (Brandsen and Pestoff 2006), contributing to personalise services (Prandini and Orlandini 2015) and to socially innovate governance arrangements and citizenship status (Ganugi 2018). Regarding co-creation, the involvement of end-users in the planning process as well as in service delivery is what distinguishes co-creation from co-production. In other words, the two terms can be distinguished on the basis of the kinds of inputs citizens contribute and, even more, on the 
basis of the phase of the production cycle-e.g. planning, implementation, delivery, and others. (Voorberg et al. 2017; Brandsen and Honingh 2016; 2018; Lember et al. 2019).

For clarification, we intend co-creation as the entire process of service conception, design, production and delivery which multiple stakeholders - at different territorial scales and institutional levels - may participate in. In the Reggio-Emilia pilot, the co-creation concerns the conception, design, production and delivery of the APP to implement and link the existing social and health services of the territory in order to prevent childhood obesity. We define co-production as the specific moment of users' involvement in the production and evaluation of the service: the APP in this case. Moreover, to examine more effectively the co-creation process, looking at the Reggio-Emilia case in particular, we define another phase: the co-design. The latter reckon on the commitment of public, private and third sector stakeholders, who are interested in collaborating for the service implementation or innovation. The analysis of this phase concerns, among other aspects, the governance arrangement developed by the participating stakeholders. In our pilot development, this phase is characterised by the formation of the consulting committee.

In order to operationalise the phases of co-design and co-production, we bring in two terms already existing in social science literature (Lockwood 1964; Mouzelis 1997; Habermas 1987; Archer 1995; 1996 and Luhmann 2013): system and social integration. Recalling Archer's words about the interrelation between System Integration and Social Integration as it was depicted by Lockwood:

Lockwood insisted on the possibility and profitability of distinguishing the orderly or conflictual relations pertaining between groups of actors (the degree of social integration) from the orderly or contradictory relations prevailing between parts of the social structure (the degree of system integration). The point of the exercise was to theorize about the interplay between them, for he rightly argued that neither element alone provided the sufficient conditions of structural change. Thus, System Integration could be low but unless its contradictions were actualized and amplified by sectional social groups, they could be contained, and stasis would persist because of this high Social Integration. Alternatively, group antagonism could be profound (low Social Integration) without leading to significant change in society, unless it was linked to Systemic contradictions. In short, it was the conjunction between the two elements which furnished the key to structural stability or change (Archer 1996, xvi-xvii).

To summarise, System Integration represents the cooperation between (representatives of) social institutions, whereas the Social Integration concerns the actual involvements of citizens (or citizen groups) within institutional processes. For our purposes, the System Integration coincides with the co-design phase: indeed, the efficiency of the co-design depends on the degree of system integration that is the ability of the stakeholders involved to negotiate their interests and identities, and to find consensus about the service to produce. The Social Integration corresponds with the co-production phase: in this case, the efficiency of co-production depends on the possibility of the parents of obese children to interact with institutional actors and to impact on the process of production and delivery of the service.

Within our framework, this means that a real process of co-creation, able to innovate the production of social and health services, is completed only when both co-production and co-design are successful, that is when the phase of co-production achieves a high level of social integration and when the phase of co-design achieves a high level of system 
integration. Alternatively, low levels of social integration or low levels of system integration accomplish different results, which are not fully co-creation (Table 3). High level of social integration between potential final users of a service, who manage to co-produce a new service or innovations for an existing service, and low levels of system integration among institutional actors, who fail in collaborating and participating, produce a "grassroot co-creation". The risk is an episode of social innovation without institutionalisation and, therefore, hardly sustainable in the long-term.

Table 3. The possible configurations emerging from different combinations of system integration and social integration. The characteristics of the co-design and the co-production phases contribute to produce diverse co-creation processes.

\begin{tabular}{|c|c|c|}
\hline $\begin{array}{c}\text { System Integration / } \\
\text { Co-design }\end{array}$ & $\begin{array}{c}\text { Low } \\
\text { System Integration / } \\
\text { Co-design }\end{array}$ \\
\hline $\begin{array}{c}\text { Social Integration / } \\
\text { Co-production }\end{array}$ & Full Co-creation \\
\hline $\begin{array}{c}\text { Social Integration / } \\
\text { Co-production }\end{array}$ & $\begin{array}{c}\text { Grassroot Co-creation } \\
\text { Co-creation in the shadow of } \\
\text { institutions }\end{array}$ & $\begin{array}{c}\text { Simulated or missing } \\
\text { Co-creation }\end{array}$ \\
\hline
\end{tabular}

On the contrary, high level of system integration achieved by institutional actors who manage to negotiate their interests and to share common objectives and low level of social integration due to a failed inclusion and participation of final users of the service result in "co-creation in the shadow of institutions". In this case, the process generates an institutional innovation, without a real integration of beneficiaries' needs, desires and interests. The last case coincides with low levels of both social and system integration, causing a "missing co-creation": final users are inadequately involved in the co-production phase and institutional actors are inadequately involved in the co-design phase. This case occurs when the service or the project is mostly developed by one institutional actor, who may activate processes of information or, worst, manipulation (Arnstein 1969), which result in simulated attempts of co-creation.

Hence, by analysing, on the one hand, the degree of system integration during the co-design phase and, on the other hand, the degree of social integration during the co-production phase of the APP in Reggio-Emilia, more elements come to light. Focusing on system integration, the variables worth analysing are:

a) who convenes the members of the consulting committee;

b) who is involved in the committee and who is not involved;

c) what practices regulate the meetings of the committee;

d) how each member participates in the negotiation.

Focusing on social integration, significant variables are:

a) the inclusion of a collective actor who represents the families

b) the degree of parents' influence on the production of the APP. 
Thus, by analysing these variables of both social and system integration, the study becomes more in-depth.

\section{The co-design phase and the formation of the consulting committee}

One of the first actions taken by the coordinator of the Reggio Emilia pilot was the stakeholder mapping to find and engage all the actors who might be interested in and affected by the production of the App. In collaboration with the partner company of information technologies and the actors who had already participated in the BMI program (the Hospital Paediatric Unit, Family paediatricians, the Food Hygiene Service, and others, as seen in figure 4), the Epidemiology Service of the Local Health Unit drafted a list of internal and external stakeholders, decision-makers, and beneficiaries of the pilot project. This activity sought to identify the contribution of each stakeholder to the process, the potential impact of the project on the stakeholders, and the potential strategies to engage each stakeholder. Based on this list, the coordinating group organised a meeting among all internal stakeholders. During the meeting, the participants proceeded to the second stakeholder analysis, eventually deciding the formation of a steering committee which included all main internal stakeholders and two experts as external advisors. The remaining stakeholders - all external and internal stakeholders, decision-makers, and parents - were included in a wider consulting committee. A third stakeholder analysis was carried out during the first committee's meeting to identify other public administration sectors and non-profit associations conducting related projects. After this initial phase, the consulting committee decided to remain open to new participants for the project's duration.

Figure 4. Evolution of the actors and stakeholders' map.

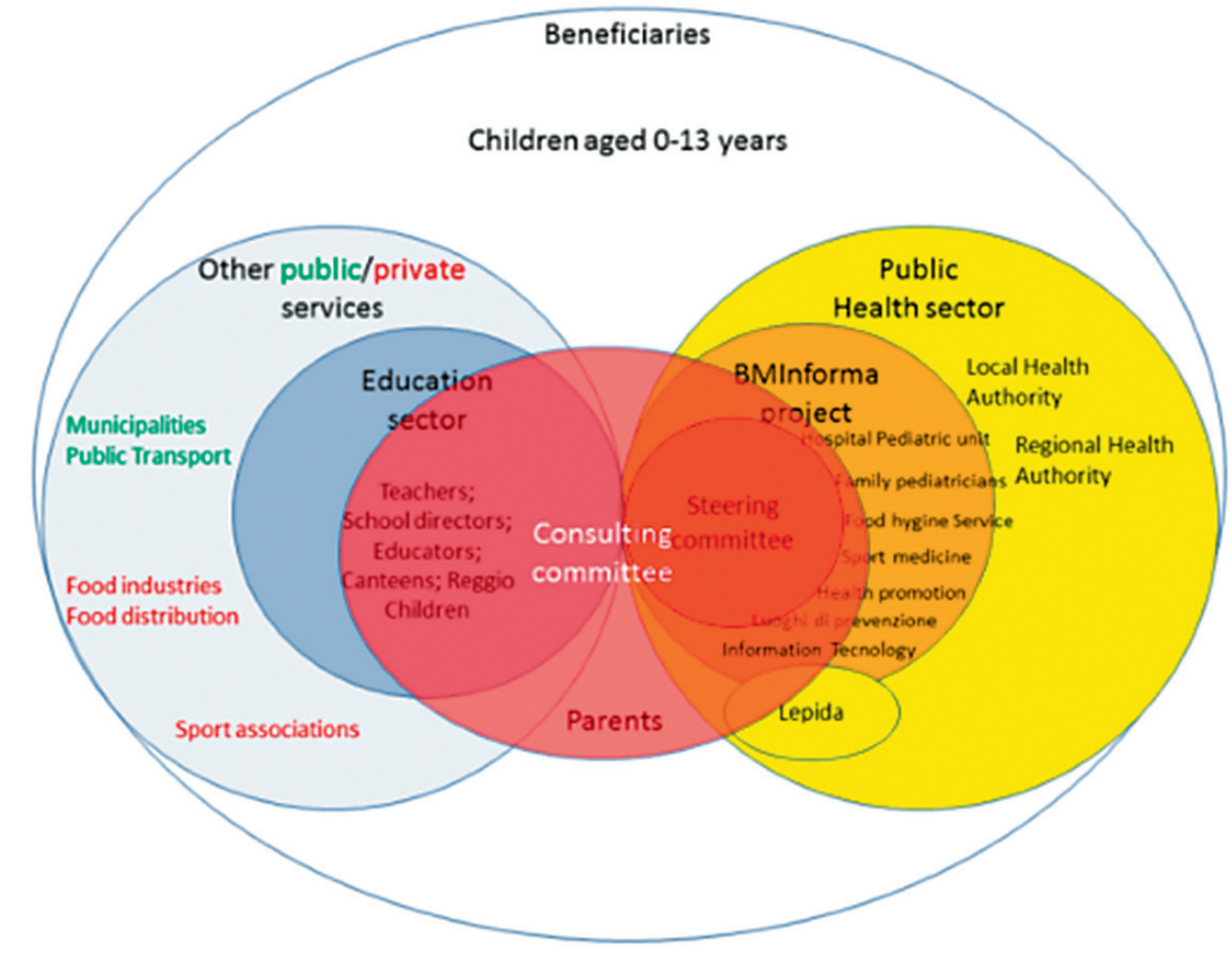

Source: Rossi et al. 2020. 
Two years after the foundation of the consulting committee, the latter was mainly full of public sector workers and organisations (e.g city of Reggio Emilia's mobility office, the alderman for personal services, health, associations and equal opportunities of towns within the province, dieticians of the local public services, and teachers from the province), as well as many Third Sector organisations (e.g. sports associations). Some actors represented food industries and food distribution companies, making up the private sector contribution.Some of the Local Health Unit affiliated members were the Information Technology Service, the Primary Care Department, the Sport medicine sector, and the Health promotion sector. As Figure 4 illustrates, the consulting committee's establishment allowed the involvement of other sectors fundamental for the children's well-being. These sectors included education, municipal administrations, social innovation, transport, sports associations, and food production/distribution industries (Rossi et al. 2020).

The consulting committee's role was representing the perspective of the actors which dealt with obesity, directly or indirectly, in the city of Reggio Emilia. The group met twice per year. Besides collecting advice from each participant, the aim of the meetings was creating an actors' network who shared experiences and suggestions about the prevention and the treatment of obesity, and also supported each other's activities/projects while gathering individual goals into a collective one. Essentially, the consulting committee contributed to the co-creation of the mobile app, providing ideas and feedback about the contents and prototype.

Therefore, the members of the consulting committee were asked to analyse the collected materials during the phase of needs assessment. Based on this material, a plenary session of the consulting committee led to a set of unstructured ideas for the mobile app. This set was further developed in a second session by summarising the materials and the ideas in three main issues: identifying all topics related to family well-being, grouping topics into overall areas that should be covered by the app and transforming needs into content within the app. Afterwards, the consulting committee was reorganised in subgroups to better deal with similar topics and technical issues. Working in smaller groups helped foster a greater participation of each stakeholder. Indeed, during the plenary sessions, the proactive participation was limited to those stakeholders whose activities and services were more affected by the development of theapp (e.g. paediatricians, dieticians and the Food and Nutrition Hygiene Service). Those stakeholders who were less directly involved children's obesity services (e.g. reading and sport associations and teachers) were more passive in their participation. The reduced number of members in each subgroup allowed all stakeholders to contribute actively to the app, for example by reporting their indirect experiences with families and children.

The process described was led and facilitated by the Epidemiology Service of the Local Health Unit, while the IT company (Lepida) implemented the consulting committee's ideas after checking their technical feasibility. This resulted in several choices taken according to the preferences and interests put forward by the stakeholders, not only about the material collected on the needs assessment phase, but also about the feedback received by the parents who tested the app prototype. Indeed, the stakeholders of the consulting committee evaluated the coherence and the priority of each parents' request. The red square in Figure 5 shows precisely the need assessment done by the consulting committee, the formulation of the stakeholders' preferences which gave shape to the content of the app to 
be delivered, and, eventually, the influences of these preferences on the steering committee and the app.

Figure 5. Co-creation strategies for the design, production, and governance of the app in the Reggio Emilia pilot project on childhood obesity prevention. The red circle highlights the influences of and on the consulting committee during the process.

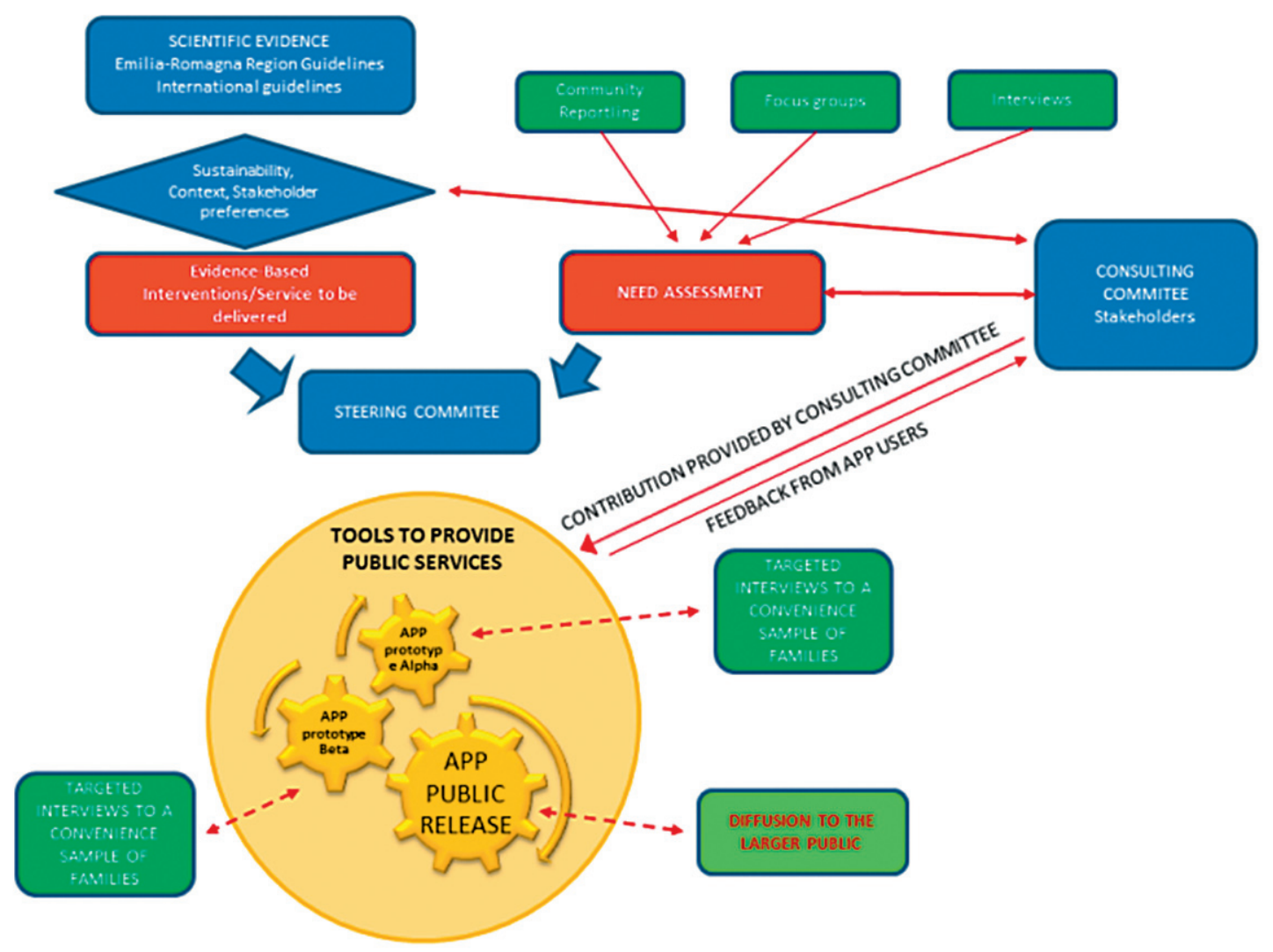

Source: Rossi et al. 2020

\section{The co-production and the involvement of families of obese children}

The stakeholders' map produced by the steering actors of the project included parents of obese children too. However, the Epidemiology Service of the Reggio Emilia Health Unit did not find any specific parent associations that focused on healthy lifestyle, obesity prevention, or child well-being, whereas it found associations focused on abuse prevention, divorce and protection of minors. Therefore, only a representative of the school parent councils participated in the consulting committee's meetings and the steering actors dealt with the absence of final users in the consulting committee through two strategies:

- The consideration that many of the stakeholders on the consulting committee were parents or grandparents of children in the target age (from new-born to pre-adolescence) and thus also potential end users (Rossi et al. 2020);

- The activation of other means of co-creation.

These co-creation tools took the form of focus groups, community reporting and public workshop. Two focus group sessions were facilitated by the researchers of the University of Bologna in October 2018, during the need assessment phase. There were five mothers in the first and five mothers in the second, aged between 30 and 50 years old. Each focus 
group discussion concerned lifestyle, physical and nutritional activities, and the role of IT in their lives.

The public workshop was organised during a national festival on digital innovation that took place in Reggio Emilia in the same period. The workshop was called "What do you need on your smartphone for your child's health?" and was organised in 4 different tables, each one focused on one issue including diet, physical activity, communication with family paediatricians, and the relationship with municipal institutions. At each table, the parents had the opportunity to converse with experts and decision makers working within the four fields and to respond to the main research question. The parent conversations were then summarised by the experts. Besides talking, the parents could leave written or audio messages using Post-It Notes and attaching them on pre-prepared stands. In the same location, a whiteboard allowed both children and parents to draw anything that came to mind. Their thoughts, comments, and answers were also stimulated by an atelier dedicated to the exploration of vegetables through all five senses. All the conversations, Post-It Notes, audio and video messages were collected.

The Community Reporting for Storytelling, a pan-European movement established in 2007 by People's Voice Media, uses digital tools to gather, curate and mobilise lived experience stories (Snowden 2016). The pilot developed three stages to better understand the welfare needs of families:

1. Community Reporting Training.

2. Story Gathering and Curation.

3. Mobilisation of insights from the parents' stories.

Nine participants, including paediatricians, researchers, and members of the pilot project steering committee were trained as Community Reporters during a two-day program held in May 2018, underpinned by peer and experiential learning strategies. From June-September 2018, the 17 stories gathered by the Community Reporters were analysed via topic, content and context before analysing these findings across the stories. These findings and some story extracts were used during a workshop of the consulting committee to stimulate co-creative conversations about the upkeep of family welfare.

Some of the solutions suggested by the exercise regarded the lack of safe public space for children to play; parents lacking time to accompany their children to physical activities, and lack of time and education in choosing a healthy diet for them and their children. Other issues concerned the action to take in case of an emergency, which parents valued as useful within the app. All parents agreed to prohibit the app's use by children.

After the phase of design and implementation of the app, the first prototype was tested by a sample of families. Between December 2019 and January 2020, University of Bologna researchers received feedback from 26 parents. The parents were composed of four Italian fathers, five foreign mothers, and 17 Italian mothers. The interviews investigated six areas:

1. Usefulness of the chosen contents.

2. The look of the app.

3. The interaction with the app.

4. The interaction between users and stakeholders.

5. Expectations about the app.

6. The parents' perception of involvement in the co-creation process. 
Each area contained both strengths/opportunities and weaknesses/threats as parents perceived them. Moreover, the interviewees were able to request more features to be implemented in the app. These requests, together with the other interview contents, were reported to the consulting committee, which evaluated the feasibility and priority of all issues raised.

\section{Discussion: Enabling and Disabling Conditions for System Integration (Co-design) and Social Integration (Co-production)}

The co-design phase among the Reggio Emilia stakeholders achieves a high degree of system integration, where multiple actors collaborate and participate to pursue a common goal. This is made more likely by the presence of a strong civic and institutional culture among the actors of the City. Indeed, all members of the consulting committee strongly believe that urban actors' work is fundamental for the common good. At the pilot's beginning, many ongoing collaborations were active in Reggio Emilia: projects carried on by schools and dieticians, schools and sports associations, the Prevention Area of the Local Health Unit and sports associations and so on.

Secondly, the steering actor who gathered all the others confirms the project's reliability and prospects for future development of the project. Indeed, the Epidemiology Service of the Local Health Unit was already working on the issue of childhood obesity, collaborating with all the other stakeholders in the BMI program. Thus, the interest in the prevention of childhood obesity was already high among the stakeholders. Those working on this problem have considered the app as in conjunction with their normal working activities; those who do not work directly on obesity but do work with families and children are aware of app's potential on children's welfare generally. Therefore, since the project's value was indisputable, all stakeholders are ready to tackle the issue of childhood obesity.

Another reason for their engagement been the low investment in terms of money, time and effort from the institutions and organisations the stakeholders are members of. In fact, the project has been presented to the stakeholders detailed and ready-made. They have been asked toto participate in two plenary meetings and in other sub-groups' meetings, to read the material collected by the need assessment and to send feedbacks and ideas, (although electronically due to the pandemic during 2020). Finally, the app does not impact excessively on their work, with the exception of paediatricians' work. Notably, the paediatricians have been the most critical and concerned about the app.

Accordingly, the resulting system integration is "tight" if we look at the complementarity of stakeholders' interests in sharing the project, but it is also "loose" if the limited amount of commitment and actions requested by the co-design phase is considered. Besides the quantifiable resources, this low investment regards also the possible app costs. Each stakeholder could have advantages by the app's development of the and by the participation in the consulting committee, while having no direct costs or impact on its own work. So, the reasons to block the project were almost non-existent.

Eventually, the forms of participation which facilitated the system integration have been the information and diffusion of the project among institutional stakeholders, and the division into thematic subgroups. The latter were chosen by the steering actor and the members of the committee could intervene to modify and implement pre-determined contents. Hence, the system integration took the shape of a committee led by a competent 
actor who gathered participants, listened to them, chose the contents suggested and eventually asks for the validation of the results: this is a consultation ${ }^{5}$ process for validation and a governance "in the shadow of supervisory institution" who drives the project.

Regarding the co-production phase the s beneficiaries' social integration proceeds in a different way. First, the civil society does not possess an internal collective actor- e.g. associations or parents' committee - focusing on childhood obesity. The existing Forum of families of Reggio Emilia does not focus on sanitary skills. Likewise, other parent groups are focused on other topics, such as abuse prevention and minors' protection. Thus, these groups were not invited to participate in the process. Consequently, the steering actor of the project involved parents as individual beneficiaries of the service, as users of the app, but it did not try to aggregate families of obese children and to include them within the consulting committee.

The tools of co-production, applied in the need assessment phase and in the prototype evaluation, were permitted to collect feedback. However, only this material entered the consulting committee and "met" the stakeholders: there has been no dialogue between parents and stakeholders. Considering this aspect and the involvement of parents as individuals and not as stakeholders, one cannot speak of an effective and adequate participation. Rather, we identify an assembly process for consultation about micro-themes. The inclusion achieved appears as paradoxical and attempted inclusion of actors who were actually excluded from the general co-creation process.

In addition, even the app interface did not facilitate a deep and full participation of Reggio Emilia's families because technical limitations meant the contents could not be translated into foreign languages. Since all stakeholders witness the difficulties in reaching minorities, the difficulty in communicating digitally brings down the potential for co-creation. By minorities, we refer to families with foreign languages and cultures, but also marginalised families or families affected by the digital divide phenomenon.

Table 4. Among the possible configurations emerging from different combinations of system integration and social integration, the project examined represents a model of co-creation in the shadow of institutions

\begin{tabular}{|c|c|c|}
\hline High & $\begin{array}{c}\text { High } \\
\text { System Integration / } \\
\text { Co-design }\end{array}$ & $\begin{array}{c}\text { Lowstem Integration / } \\
\text { Co-design }\end{array}$ \\
\hline $\begin{array}{c}\text { Social Integration / } \\
\text { Co-production }\end{array}$ & Full Co-creation \\
\hline $\begin{array}{c}\text { Social Integration / } \\
\text { Co-production }\end{array}$ & $\begin{array}{c}\text { Grassroot Co-creation without } \\
\text { institutionalisation }\end{array}$ \\
\hline $\begin{array}{c}\text { Co-creation in the shadow of } \\
\text { institutions-Reggio Emilia } \\
\text { pilot }\end{array}$ & Simulated or missing \\
\hline
\end{tabular}

Eventually, the app project is part of prevention and health promotion intervention: these activities, aimed at changing risky behaviours, are not perceived as necessary by the

5 We refer to consultation as conceptualized by Arnstein (1969) within the structure of the ladder of participation. 
target population. The latter often perceive these interventions as unwelcome intrusions (Rossi et al. 2020).

In a nutshell, recalling the possible combinations emerging from the relation between the system integration in the co-design phase and the social integration in the co-production phase, the project in Reggio Emilia is characterised by a low level of social integration and a high level of system integration. The result is a process of co-creation developed in the shadow of institutions.

The co-creation is mostly applied during the co-design phase thanks to effective integration among stakeholders, whereas the co-production phase unfolds with a low participation of families. Even if the families are listened to and empowered to intervene on the final product of the service - the app - they are neither integrated as a collective actor, nor integrated within the consulting committee. Moreover, the steering actor or the consulting committee do not disseminate the project publicly, communicating the open process and the willingness to involve potential final users widely within the region. Since the second version of the app is under implementation and evaluation, other analysis will follow in order to examine the whole process until the end. Therefore, the co-creation process might produce an institutional innovation, but not a real social innovation.

\section{References}

Archer, M.S. 1995, Realist Social Theory: The Morphogenetic Approach, Cambridge University Press, Cambridge. doi:10.1017/CBO9780511557675.

Archer, M.S. 1996, Culture and Agency. The Place of Culture in Social Theory, Cambridge University Press, Cambridge.

Arnstein, S.R. 1969, A Ladder of Citizen Participation, Journal of the American Planning Association, vol. 35, no. 4, pp.216-224.

Attwood, H. 1997, An overview of issues around the use of participatory approaches by post-graduate students, in IDS, Participatory Research, IDS PRATopic Pack Brighton: IDS, University of Sussex.

Bovaird, T. 2007, Beyond Engagement and Participation: User and Community Coproduction of Public Services, Public Administration Review, pp. 846-860.

Boyle, D. \& Harris M. 2009, The Challenge of Co-production. How equal partnerships between professionals and the public are crucial to improving public services, NEF, London.

Brandsen, T. \& Honingh, M. 2016, Distinguishing Different Types of Co-Production: A Conceptual Analysis Based on the Classical Definition, Public Administration Review, vol. 76, no. 3, pp. 427-435.

Brandsen, T. \& Honingh, M. 2018, Definitions of Co-Production and Co-Creation, in T. Brandsen, T. Steet, \& B. Verschuere (eds.), Co-Production and Co-Creation: Engaging Citizens in Public Services, Routledge, London.

Brandsen, T. \& Pestoff, V. 2006, Co-production, the third sector and the delivery of public services. An introduction, Public Management Review, vol. 8, no. 4, pp. 493-501.

Fung, A. 2015, Putting the Public Back into Governance: The Challenges of Citizen Participation and Its Future, Public Administration Review, vol. 75, no. 4, pp. 513-522.

Ganugi, G. 2018, The Role of Commoning and Mutually Shaped Citizenship in Developing Bottom-Linked Governance. The Projects Living Street and Future Street in Belgium, Sociologia e Politiche Sociali, vol. 21, pp. 51-70. 
Gill, H., Purru, K. \& Lin, G. 2012, In the Midst of Participatory Action Research Practices: Moving towards Decolonizing and Decolonial Praxis, Reconceptualizing Educational Research Methodology, vol. 3, no. 1

https://journals.hioa.no/index.php/rerm/article/view/357/361

Giorgi Rossi P., Ferrari F., Amarri S., Bassi A., Bonvicini L., Dall'Aglio L., Della Giustina C., Fabbri A., Ferrari A.M., Ferrari E., Fontana M., Foracchia M., Gallelli T., Ganugi G., Ilari B., Lo Scocco S., Maestri G., Moretti V., Panza C., Pinotti M., Prandini R., Storani S., Street M.E., Tamelli M., Trowbridge H., Venturelli F., Volta A., Davoli A.M., Childhood Obesity Prevention Working Group undefined, 2020, Describing the Process and Tools Adopted to Cocreate a Smartphone App for Obesity Prevention in Childhood: Mixed Method Study, JMIR Mhealth Uhealth, vol. 8, no. 6, e16165.

Habermas, J. 1987, The Theory of Communicative Action: Reason and the Rationalization of Society, Vol. 1-2. Wiley.

Hartley, J. 2005. Innovation in governance and public services. Public Money \& Management, vol. 25, no. 1, pp. 27-34.

Hood, C. 1991, A public management for all seasons? Public Administration, vol. 69, no. 1, pp. 3-19.

Lember, V., Brandsen, T. \& Tõnurist, P. 2019, The potential impacts of digital technologies on co-production and co-creation, Public Manangement Review, vol. 21, no. 11, pp. $1665-1686$.

Lockwood, D. 1964, Social Integration and System Integration, in G.K. Zollschan and H.W. Hirsch (eds.), Explorations in Social Change. Boston: Houghton Mifflin.

Luhmann, N. 2013, Theory of Society, vol. 2, Stanford University Press, Stanford.

MacDonald, C 2012, Understanding participatory action research: A qualitative research methodology option, The Canadian Journal of Action Research, vol. 13, no. 2, pp. 34-50.

Mouzelis, N. 1996, Social and System Integration: Lockwood, Habermas, Giddens, Sociology, vol. 31, no. 1, pp. 111-119. doi:10.1177/0038038597031001008.

Osborne S., Radnor Z. \& Strokosch K. 2016, Co-Production and the Co-creation of Value in Public Services: A suitable case for treatment?, Public Management Review, Vol. 18, no. 5, pp. 639-653.

Ostrom, E. 1996, Crossing the Great Divide: Coproduction, Synergy, and Development. World Development, vol. 24, no. 6, pp. 1073-1087.

Prandini, R. \& Orlandini, M. 2015, Personalizzazione vs individualizzazione dei servizi di welfare: fasi, attori e governance di una semantica emergente, Studi di sociologia, vol. 4, pp. 353-373.

Smith, L., Bratini, L., Chambers, D.A., Jensen, R.V. and Romero, L. 2010, Between idealism and reality: Meeting the challenges of participatory action research, Action research, vol. 8, no. 4, pp. 407-425.

Snowden D. 2016, Story-telling: an old skill in a new context, Business Information Review, vol. 16, no. 1, pp. 30-37. doi:10.1177/0266382994237045.

Torfing, J., Sørensen, E. \& Røiseland, A. 2019, Transforming the Public Sector into an Arena for Co-Creation: Barriers, Drivers, Benefits, and Ways Forward, Administration \& Society, vol. 51, no. 5, pp. 795-825.

Tuurnas S. 2015, Learning to co-produce? The perspective of public service professionals, International Journal of Public Sector Management, vol. 28, no. 7, pp.583-598, https:// doi.org/10.1108/IJPSM-04-2015-0073. 
Voorberg, W., Bekkers, V., Flemig, S, Timeus, K., Tonurist, P. \& Tummers, L. 2017, Does co-creation impact public service delivery? The importance of state and governance traditions. Public Money \& Management, vol. 37, no. 5, pp. 365-372, https://doi.org/10. 1080/09540962.2017.1328798.

Williams, B.N., Kang, S.C., \& Johnson, J. 2016, (Co)-Contamination as the Dark Side of Co-Production: Public value failures in co-production processes, Public Management Review, vol. 18, no. 5, pp. 692-717. 